Journal of Anatolian Environmental and Animal Sciences

(Anadolu Çevre ve Hayvancıllk Bilimleri Dergisi)

DOI: https://doi.org/10.35229/jaes.655016

\title{
Medaka (Oryzias latipes) Glukoz 6 Fosfat Dehidrogenez (g6pd) Geninin Genomik Organizasyonu
}

\author{
Mehtap BAYIR* \\ Atatürk Üniversitesi, Ziraat Fakültesi, Tarımsal Biyoteknoloji Bölümü, ERZURUM
}

Atıf yapmak için: Bayır, M. (2020). Medaka (Oryzias latipes) Glukoz 6 Fosfat Dehidrogenez ( $g 6 p d$ ) Geninin Genomik Organizasyonu. Anadolu Çev. ve Hay. Dergisi, 5(1), 38-44.

How to cite: Bayır, M. (2020). Genomic Organisation of Glucose 6 Phospate Dehidrogenese ( $g 6 p d)$ Gene of Medaka (Oryzias latipes). J. Anatolian Env. and Anim. Sciences, 5(1), 38-44.

DD: https://orcid.org/0000-0002-7794-1058

\section{*Sorumlu yazarın:}

Mehtap BAYIR

Atatürk Üniversitesi Ziraat Fakültesi Tarımsal

Biyoteknoloji Bölümü, Erzurum, TURKIYE

\: mehtap.bayir@atauni.edu.tr

Cep telephone : $+90(544) 6769187$
Öz: Ekzotermik canlılar, serbest radikallerin zararlı etkilerinden korunabilmek için güçlü enzimatik ve enzimatik olamayan antioksidan savunma sistemine gereksinim duyarlar. Çalıșmada Glukoz 6 fosfat dehidrogenez $(g 6 p d)$ enzim geninin tercih edilme nedeniyse, antioksidan savunma sistemin temel enzimlerinden birisi olmasıdır. Araştırmada medaka (Oryzias latipes) g6pd geninin yapısı (ekson ve intron dizilimleri, TATA kutusu, CAAT kutusu, Poli A kuyruğu) belirlenmiş, bu genin transkribe ettiği amino asitler tespit edilmiş ve diğer omurgalılarda aynı gen tarafından üretilen protein dizilimleri NCBI veri tabanı ve ENSEMBL veri tabanlarından elde edilerek Bioedit programında dizileme işlemi yapılmış, benzerliközdeşlik oranları \% olarak hesaplanmış ve tablo olarak verilmiştir. Ayrıca yine elde edilen protein dizilimleri esas alınarak, BioEdit yazılımı ve MEGA6 programı kullanılarak, medaka (O. latipes) ve diğer bazı omurgalılar arasındaki filogenetik ilişki belirlenmiştir. Medaka g6pd geninde bulunan, plati balı̆g (Xiphophorus maculatus), zebra baliği (Danio rerio), balon baliği (Fugu rupripes), şişen balık (Tetraodon nigoviridis) ve insan (Homo sapiens) g6pd/G6PD genlerinin kromozomlar üzerinde bulundukları bölgeler belirlenerek manuel olarak korunmuş gen sentezi dizayn edilmiştir. Teleost balıkların stres oluşturan etmenlere karşı vermiş oldukları tepkiler, moleküler çalışmalarla ölçülmesi mümkün olan tepkilerdir ve dolayısıyla çalışılan türün genetik özelliklerinin belirlenmesi biyoteknolojik çalışmalar bakımından oldukça önemlidir. Bu nedenle biyoenformatik veri tabanları ve programlar kullanılarak medaka (O. latipes) g6pd geninin karakterizasyonu ve identifikasyonu yapılmıştır. Böylece balıkların moleküler stres cevabı çalışmalarında kullanılabilecek öncü veriler, bu araştırma ile bilim dünyasına sunulmuştur.

Anahtar kelimeler: Medaka, biyoenformatik, model organizma.

\section{Genomic Organisation of Glucose 6 Phospate Dehidrogenese (g6pd) Gene of Medaka (Oryzias latipes)}

*Corresponding author's: Mehtap BAYIR

Atatürk Üniversitesi Ziraat Fakültesi Tarımsal Biyoteknoloji Bölümü, Erzurum, TURKIYE

$凶:$ mehtap.bayir@atauni.edu.tr

Cep telephone : $+90(544) 6769187$

\begin{abstract}
Exothermic organisms need a strong enzymatic and non-enzymatic antioxidant defense system in order to be protected from the harmful effects of free radicals. The reason of Glucose 6 phosphate dehydrogenesis $(g 6 p d)$ enzyme gene is preferred in the study that this enzyme is one of the essential enzymes of the antioxidant defense system. In the study, the structure of the medaka (Oryzias latipes) g6pd gene (exon and intron sequences, TATA box, CAAT box, Poly A tail) was determined, amino acids transcribed by this gene were detected and protein sequences produced by the same gene in other vertebrates were recorded using data obtained from NCBI and ENSEMBL database, and the sequence of similarity-identity (\%) was calculated and given as a table. Furthermore, based on the obtained protein sequences, the phylogenetic relationship between the medaka (O. latipes) and some other vertebrates was determined using BioEdit software and MEGA6 program. Conserved gene synthesis was designed by manually identifying the regions on the chromosomes of zebrafish, fugu, stickleback, platyfish and human g6pd genes of the conserved genes identified in the medaka. The responses of teleost fish to stress factors are possible to be measured by molecular studies and therefore it is very important for biotechnological studies to determine the genetic characteristics of the species studied. For this reason, characterization and identification of $g 6 p d$ gene was performed by using bioinformatics databases and programs. thus, the pioneering data that can be used in molecular stress response studies of fishes have been presented to the scientific world with this research.
\end{abstract}

Keywords: Medaka, bioinformatics, model organism. 


\section{GİRIŞ}

Medaka (Oryzias latipes), Doğu Asya'da yaşayan ve genellikle su, gölet ve çeltik tarlaları gibi tatlı sularda bulunan küçük bir balıktır (Hori, 2011). Medaka (Oryzias latipes)'nın fizyolojisi, embriyolojisi ve genetiği son 100 yıldır yoğun bir şekilde çalışılmakla beraber, son yıllarda bu organizmada yapılan çalışmalar, erken gelişim, pigmentasyon, cinsiyet belirleme ve insan hastalıkları için genetik model sistemler olarak kullanılması ve bu balığın biyolojik geçmişi üzerine odaklanmıştır (Naruse et al., 2011). Yamamoto (1951), ilk olarak, medaka için cinsiyet bağlantı haritasını oluşturmuş ve cinsiyetler arasındaki rekombinasyon sıklığındaki farklılıkları tanımlamıştır. Ayrıca ilk defa, balıklarda i ve ci losi arasında otozomal bağlantı olduğunu bildirmiştir. PCR teknolojisinin gelişmesinin ardından, medaka, zebra balığı, kirpi balığı ve diğer balık türlerinde genetik bir bağlantı haritası oluşturmak için birkaç girişimde bulunmuş ve bu deneylerin ilk aşamalarında, önceden herhangi bir genom bilgisi gerektirmediğinden parmak izi (finger-print) tipi işaretleyiciler kullanılmıştır. Daha sonraki aşamalarda, genomun spesifik bölgelerini, sekans bilgisi varlığında çoğaltan tek lokuslu markörler kullanılmış ve etkinleştirilmiş tek lokuslu markörler kullanılarak oluşturulan harita ortolog genler arasındaki bağlantı ilişkilerini karşılaştırmak için kullanılmıştır. Ardından teleostlara spesifik tüm genom çoğaltması uygulanmıştır (üçüncü WGD). Son olarak, tetraodon genom projesine ilaveten medaka genom sekanslama projesi hem medaka hem de tetraodon için yüksek kalitede bir taslak genom sekansı sağlamıştır. Tüm bu veriler, proto-kromozomların duplikasyonundan önce yeniden yapılanması ve mevcut medaka, tetraodon ve zebra balığı genomlarının oluşumuna yol açtığı potansiyel bir senaryoyu ortaya koyan üçüncü WGD’yi doğrulamıştır. Bu analiz ayrıca, teleost (kemikli) balıklarda mevcut ortolog genlerin korunmuş gen sentezini de tanımlamıştır. Son 100 yılda medakada yapılan araştırmalar, çok sayıda önemli biyolojik kaynak sağlamıştır. İlk kaynak, kaynaklardan ilki turuncu-kırmızı ve beyaz medaka gibi gövde rengi mutasyonlarını içermiştir.

Stres cevabının ölçülmesinin önemli bir kolu nitrik oksit (NO) ve hidrojen peroksit $\left(\mathrm{H}_{2} \mathrm{O}_{2}\right)$ gibi hücresel oksidasyon radikallerinin meydana getirdiği zararlardır. Oksijen biyolojik sistemlerde, organizmalar için elzem bir bileşik (Buechter, 1988) olmakla beraber canlı hücrelerinin tamamı, serbest radikaller adı verilen oldukça reaktif olan oksijen türevlerini de (ROS) oluşturabilmektedirler. (Halliwell, 1991; Bartosz, 2003). Canlı sistemlerde oluşturulan bu ROS'ler biyolojik olarak yararlı molekülleri okside ederek normal hücre ve doku fonksiyonlarında değişikliklere yol açabilirler. $\mathrm{Bu}$ oksidasyon oldukça kompleks bir sistem olan antioksidan savunma sistemi
(ASS) tarafindan minimize edilir. Bu sebeple, aerobik hücrelerde ve dokularda ROS üretimi, molekül oksidasyonu ve antioksidan tüketiminin kararlı bir durumu sürekli olarak devam eder (Filho et al., 2000). Normalde oksidasyon seviyesi, normal hücresel homeostatik mekanizmaları üzerindeki zararlı etkileri nedeniyle hücre içinde sıkı bir şekilde kontrol edilir. Oksidatif dengeyle alakalı metabolik yollardaki hemostatik dengelere bağlı olan gen ekspresyonundaki düzensizlik kanser, yaşlanma, ailevi ve yaşa bağlı hastalıklarının pek çoğu ile bağlantılı olup, bu bakımdan omurgalı türlerin büyük çoğunluğunda stres tepkilerinin düzenlenmesinde bu genler oldukça büyük öneme sahiptirler (Lushchak, 2011). Hücrelerde serbest oksijen radikallerinin düzenlenmesinde pekçok önemli gen yollarının rol oynadığı bilinmektedir. Bunlar arasında antioksidan enzimler predominant olanlardandır. $\mathrm{Bu}$ genler süperoksit üretiminin bir sonucu olarak metabolik yolda $\mathrm{H}_{2} \mathrm{O}_{2}$ üretilmesine neden olurlar (Trachootham et al., 2008). Hücreler, bir takım koruyucu mekanizmalara sahiptir ve bu mekanizmalar özellikle hücreleri serbest oksijen radikallerinin zararlı etkilerinden korur. Antioksidan sistemler hücreyi oksidatif strese karş1 korumakla yükümlü olup, serbest radikaller kadar çeşitlidirler. Antioksidan enzimlerden biri olan G6PD, temel görevi NADPH üretmek olan PPP'nin ilk basamağını katalizleyen anahtar enzimdir (Pilz et al., 1984; Keha \& Küfrevioğlu, 1997; Lehninger, 2000, Aytekin \& Kargın, 2019). DNA'nın , steroidlerin, yağ asitlerinin, bazı aminoasitlerin ve indirgenmiş glutatyonun sentezinde kullanılan NADPH'lar (Bonsignore et al., 1966; Bonsignore \& Flora, 1972) aynı zamanda hücrede hidrojen ve elektron kaynağı olarak görev yapmakta ve hem büyüme hem de üreme proseslerinde esansiyel bir bileşik olarak görev yapmaktadır (Kan et al., 1988). Glikoz-6fosfat dehidrojenaz, nükleotit öncüleri ve NADPH de dahil olmak üzere çeşitli temel moleküllerin üretilmesinden sorumlu korunmuş bir yol olan pentoz fosfat yolunun ilk enzimidir (Miclet et al., 2001). NADPH, birçok oksidatif stresin düzenlenmesinde rol oynayan enzimler tarafından, birçok hücresel reaksiyonda kullanılan önemli bir elektron kaynağıdır. Buna göre, bu yardımcı faktör, en az üç antioksidan yolağında, glutation, tioredoksin ve glutaredoxin döngülerinde rol oynar. Glutatyon döngüsünde, NADPH, glutatyon disülfit (GSSG)'e oksidasyonundan sonra serbest radikal temizleyici molekül glutatyonunu (GSH) yeniler. NADPH'den gelen elektronlar, iki GSH molekülü serbest birakmak üzere GSSG'nin ayrıldığı glutatyon redüktaz tarafından katalize edilen reaksiyon sirasinda serbest birakilırlar. NADPH, diğer antioksidan yollaklarında da benzer bir rol oynamaktadır (Becker et al., 2003). G6PD enzim aktivitesi balıklarda özellikle beslenme ve çevresel şartlarla 
değişiklik göstermektedir ve bu enzimin aktivitesinde olabilecek olağan dışı değişiklikler balık metabolizmasında önemli marazlara yol açabilmektedir (Bayır, 2002).

Çalışmada plati balığı (Xiphophorus maculatus), zebra baliği (Danio rerio), balon baliği (Fugu rupripes), şişen balık (Tetraodon nigoviridis) ve insan (Homo sapiens) $g 6 p d / G 6 P D$ genlerinin kromozomlar üzerinde bulundukları bölgeler belirlenerek manuel olarak korunmuş gen sentezi dizayn edilmiştir. Teleost (kemikli) balıkların stres oluşturan etmenlere karşı vermiş oldukları tepkiler, moleküler çalışmalar ile ölçülmesi mümkün olan tepkilerdir. Dolayısıyla çalışılan türün, genetik özelliklerinin belirlenmesi bakımından biyoteknolojik çalışmalar oldukça önemlidir. Bu nedenle biyoenformatik veri tabanları ve programları kullanılarak medaka $(O$. latipes) g6pd geninin karakterizasyonu ve identifikasyonu yapılmıştır. Yapılan bu araştırma ile balıkların moleküler stres cevabı çalışmalarında kullanılabilecek, öncü verilerin bilim dünyasına sunulması amaçlanmıştır.

\section{MATERYAL VE METOT}

Biyoenformatik Analizler: Glukoz 6 fosfat dehidrogenez $(g 6 p d)$ geninin fonksiyonel bir gen olup olmadığını belirlemek için NCBI veri tabanı (http://www.ncbi.nlm.nih.gov/)'nda, gene ait cDNA dizilimi kullanılarak blastma (http://blast.ncbi.nlm.nih.gov) işlemi yapılmıştır. Bu genin fonksiyonel bir gen olduğu doğrulandıktan sonra, geninin tanımlanması ve karakterizasyonu için, ENSEMBL, NCBI, EXPASY gibi veri bankaları kullanılmıştır. Çalışmada gopd genin bir tane izoformu olduğu tespit edilmiştir.

Araştırmada, medaka (O. latipes) g6pd genine ait korunmuş gen sentezi olușturmak amaciyla öncelikle bu genin kromozom bölgesi tespit edilmiștir. Daha sonra bu kromozom bölgesinde bulunan diğer genlerin, zebra baliği (Danio rerio) ve insan (Homo sapiens)'da mevcut gen bölgeleri tespit edilmiş ve korunmuş gen sentezi dizayn edilmiştir (Şekil 1).

CLUSTALW (Thompson et al., 1994) BioEdit programı (http://www.mbio.ncsu.edu/bioedit/page2.html) kullanılarak, medaka (O. latipes) g6pd geninin diğer bazı omurgalılarla filogenetik yakınlığı tespit edilmiştir (Şekil 2).

Filogenetik ağaç dizaynında zebra balığı (Danio rerio), balon balığ (Tetraodon nigroviridis), makobe ada çiklidi (Pundamilia nyererei), insan (Homo sapiens), adi sazan (Cyprinus carpio), dikenli balık (Gasterosteus aculeatus), fare (Mus musculus), tavuk (Gallus gallus), elektrikli yılan balığı (Electrophorus electricus) g6pd protein sekansları kullanılmıştır. Adı geçen canlılara ait protein dizilimleri Bioedit programında hizalanmış ve daha sonra MEGA6 (Tamura et al., 2013) programı kullanılarak, dış grup olarak zebra balığı (Danio rerio) $\mathrm{Cu} / \mathrm{Zn}$ superoksit dismutaz geni (Sodl)'in kullanıldığı filogenetik ağaç, maksimum olasılık metoduna göre dizayn edilmiştir (Kell et al., 2018).

Medaka (O. latipes) g6pd gen diziliminin tespiti için, ensembl veri bankası kullanılmıştır. $\mathrm{Bu}$ veri tabanındaki tek cDNA transkripti olan ENSORLT00000015543.2 kullanılmıştır. Medaka ( $O$. latipes) $g 6 p d$ geninin ekson ve intronları, eksonların üretmiş oldukları aminoasitler, g6pd geninin 5' ve 3' uçları ve bu bölgede bulunan, transkripsiyon olayında önemli rolü olan yapılardan TATA kutusu ve poli A kuyruğu ile transkripsiyonun başlangıç noktası $(+1)$, dizayn etmiş olduğumuz gen yapısı üzerinde gösterilmiştir (Tablo 1).

\section{BULGULAR}

Biyoenformatik Analizler: Omurgalıların stres tepkileri, gerek akut gerekse kronik durumlarda karakterize edilebilen fizyolojik yollar arasındaki farklı etkileşimleri de kapsar. Balıkların akut stres yanıtı çevredeki değişikliklerle (örneğin zararlı bir kimyasalla temas, aniden artan sıcaklık veya tuzluluk vs.) beraber değişir (Iwama et al., 1999). Balıkların yaşam ortamları olan suda zaman zaman meydana gelen olumsuzluklardan olan $\mathrm{pH}$ ve sıcaklık değişimleri ve oksijen yetersizliği gibi stres etmenleri proteinlerin fonksiyonel yapılarının değișimine neden olmakta ve protein katlanmalarında açılmalar meydana gelebilmektedir. Bunun sonucunda ise bu proteinler hücredeki farklı proteinlerle kümeler meydana getirebilir. Sonuçta uyum bozukluğu dolayısıyla proteinlerde fonksiyon kaybı gerçekleşir (Basu et al., 2000). Dolayısıyla balıkların maruz kalma olasılığı yüksek olan bu tip stres faktörlerinin antioksidan enzim genlerinin ekspresyonlarında meydana getireceği değişiklik oldukça önemlidir. Ayrıca çeşitli genlerin ve proteinlerin çevresel stres faktörlerine karşı cevaplarının belirlenmesi ve farklı seviyelerde nasıl tanımlandıklarını anlamak için deneysel kanıtlardan önce biyoenformatik çalışmaların tamamlanmış olmasına ihtiyaç duyulur. Medaka $(O$. latipes) model organizma olarak büyük önem taşıyan bir organizma olduğu için, g6pd antioksidan enzim geninin ayrıntılı biyoenformatik çalışmasının yapılması büyük önem taşımaktadır. Yapılan bu araştırmada, medaka balığının g6pd genine ait ayrıntılı biyoenformatik çalışmalar tamamlanarak hem balık fizyolojisi çalışmalarına hem de model organizma olması açısından diğer pek çok akvakültür çalışmasına sunulacak temel biyoenformatik veriler paylaşılmıştır. 
Biyoenformatik çalışmalar kapsamında, öncelikle g6pd geninin genomik verilerine ulaşmak için ENSEMBL, UNIPROT ve NCBI veritabanları kullanılmış ve istatistiksel değerlendirmeler için BioEdit yazılımı, BLOSUM62 matris programı ve MEGA6 programı bilgisayarlı algoritmalar dan yararlanılmıştır. Ensembl veri tabanından medaka balığının g6pd genine ait cDNA sekansı elde edildikten sonra yine aynı veri tabanı kullanılarak bu genin ekson (13 tane) ve intronlarına (12 tane) ulaşılmıştır. Genin 514 amino asit ürettiği tespit edilmiş olup, bu amino asitler ve hangi eksonlar tarafından üretildiği Tablo 1' de gösterilmiştir. İntronlarının hepsinin gt-ag kuralını takip ettiği görülmüştür. Belirlemiş olduğumuz gen yapısında intronlar, 5' ve 3' uçları küçük harflerle, eksonlar ise büyük harflerle gösterilmiştir. Protein üretimin metiyonin ile başladığı ve stop kodonunun ise TAA olduğu tespit edilmiştir.

Tablo 1. Medaka (Oryzias latipes) glukoz 6 fosfat dehidrogenez gen yapıs1.

Table 1. Gene structure of Medaka (Oryzias latipes) $g 6 p d$ gene. cccca 1. Gene structure of Medaka (Oryzias latipes) grpd gen ctgcagagaagagctaaaaccacgcccgccct tattactgt tagaaacaggaatgtgtac

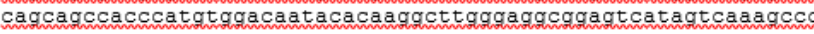

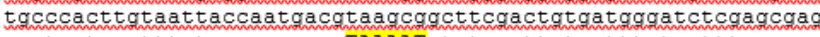

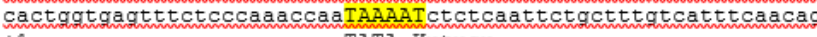
+1 TATA Kutusu

GGAAGTAGACAGCACACAAATCTGAAACAAACGCCCGGTTCTGCTGTCAGTTCAGTCTGC ACACACAGGCTGTGTTCTGTCTGCGAGTCAGTCTTTCCTCACGGCTTAACCGGCGGTTTG TCTCCTTTGGCT gtgagN1 768 tt tagAGAAAATGAATCGCCTTCCCCTCTCTCGCTCTG -M--N--R--L--P--L--S--R--S-AAGTGTTTGGAGAACTGAGGAAGGAGCTTTACGATGATGAGGAGTTCCACCAATCAGATG E--V--F--G--E--L--R--K--E--L--Y--D--D--E--E--F--H--Q--S--D-$\frac{\text { TGCATATCTTCATCATCATGGGAGCATCGgtaagN } 3327 \text { tgtagGGGGATCT GGCCAAGA }}{\text { V--H--I--F--I--I--M--G--A--S- }}$ AAAAGATCTACCCAACTCTTTGgt gagN68t gcagGTGGTTGTTCAGAGACGGACTCCTC K--K--I--Y--P--T--L--W --W--L--F--R--D--G--L--LCCCGAATCGACCTTTTTTGTCGGCTTTGCCCGCTCTGACTTGACCGTCGACGCCATACGA

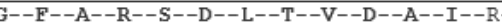
ACCGGGTGCATGCCATACATGAAGg taaaN90 cacagGTGGCGGACACGGAAGCAGACCG -T--G--C--M--P--Y--M--K- -V--A--D--T--E--A--D--R CTTGTCAGTCTTCTTCAGCAGGAACTCGTACATCAGTGGGAAATATGCAGATGAGAGCTC --L--S--V--F--F--S--R--N--S--Y--I--S--G--R--Y--A--D--E--S--S CTTCTCCAAGCTTAACTCGCACATCCTGTCTCTCCCTGGAGGAAACGAGGCCAACCGCCT --F--S--K--L--N--S--H--I--L--S--L--P--G--G--N--E--A--N--R--L CTTCTACCTGGCCCTGCCGCCGACCGTCTACCACGACGTGACCAAAAACCTCAAACTGCA --F--Y--L--A--L--P--P--T--V--Y--H--D--V--T--R--N--L--R--L--

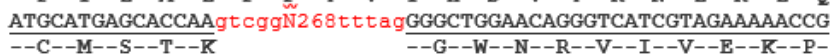
TTTGGACATG ATCTTCAGAGCTCAGAGGAGCTCTCCTCCCATCTGTCTTCTCTTTTTGC -F--G--H--D--L--Q--S--S--E--E--L--S--S--H--L--S--S--L--F--ACGAGGACCAGATTTACCGCATCGATCATTATCTGGGCAAAGAAATGGTGCAGAATCTCAT -E--D--Q--I--Y--R--I--D--H--Y--L--G--R--E--M--V--Q--N--L--MGGTGCTCAGgtgagN346tacagGTTTGGGAACCGAATCTTTGGACCAATCTGGAACAGA -V--L--R- - $\quad$ F--G--N--R--I--F--G--P--I--W--N--RGACAGTGTGGCATGCGTTGTTCTTACTTCAAAGAACCTTTTGGCACTCAGGGGCGAGGAG GCTACTTTGATGATTTTGGTATCATTCGgtaagN328atcagAGATGTCATGCAGAACCA G--Y--F--D--D--F--G--I--I--R

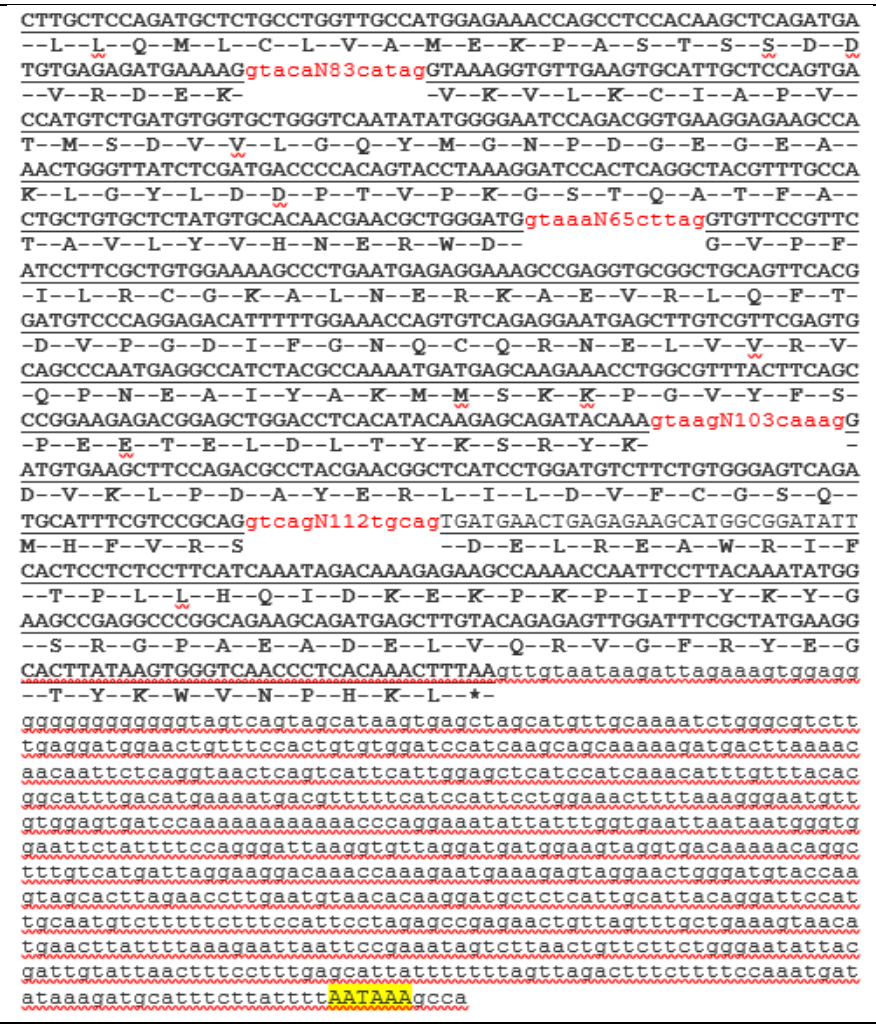
CTTGCTCCAGATGCTCTGCCTGGTTGCCATGGAGAAACCAGCCTCCACAAGCTCAGATGA TGTGAGAGATGAAAAGgtacaN83catagGTAAAGGTGTTGAAGTGCATTGCTCCAGTGA --V--R--D--E--RT--M--S--D--V--V--L--G--Q--Y--M--G--N--P--D--G--E--G--E--A-AACTGGGTTATCTCGATGACCCCACAGTACCTAAAGGATCCACTCAGGCTACGTTTGCCA K--L--G--Y--L--D--D--P--T--V--P--K--G--S--T--Q--A--T--P--A-T--A--V--L--Y--V--H--N--E--R--W--D-ATCCTTCGCTGTGGAAAAGCCCTGAATGAGAGGAAAGCCGAGGTGCGGCTGCAGTTCACG I -D--V--P--G--D--I--F--G--N--Q--C--Q--R--N--E--L--V--V--R--VCAGCCCAATGAGGCCATCTACGCCAAAATGATGAGCAAGAAACCTGGCGTTTACTTCAGC CCGGAAGAGACGGAGCTGGACCTCACATACAAGAGCAGATACAAAgtaagN1 03 caaagG ATGTGAAĞCTTCCAGACGCCTACGAACGGTCATCCTGGATGTCTTCTGTGGGAGTCAGA

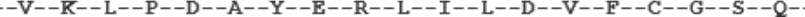
TGCATTTCGTCCGCAGgtcagN112tgcagTGATGAACT GAGAGAAGCATGGCGGATAT CACTCCTCTCCTTCATCAAATAGACAAAGAGAAGCCAAAACCAATTCCTTACAAATATGG --T--P--L--L--H--Q--I--D--K--E--R--P--R--P--I--P--Y--K--Y--G AAGCCGAGGCCGGCAGAAGCAGATGAGCTTGTACAGAGAGTTGGATTTCGCTATGAAGG

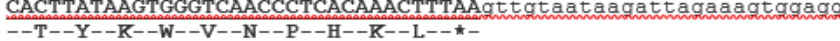
gqgqgqgqgqg tagtcagtagcataagtgagctagcatgt tgcaaaatctgqgcgtct tgaggatgqaactgtt tccactgtgtggatccatcaagcagcaaaagatgact taaaa aacaattctcaggtaactcagtcat tcat ggagctcatccatcaaacatt tgt t taca ggcatt tgacatgaaaatgacgtt t tcatccattcctggaaact t taagggaatgt

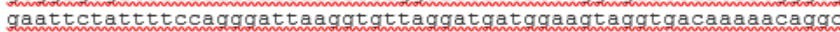
ttt ttcatgatt aggaaggacaaaccaaagaatgaaagagtaggaact gqgatgt accaa

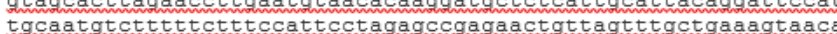
gattgtattaacttcctttgagcattattttttagttagactttctttccaaatga ataagatgcat t t $t$ tat $t$ tAATAAAgcca

*Medaka balı̆̆ı (Oryzias latipes) glukoz 6 dehidrogenez ( $g$ 6pd) geni. Ekzonları büyük harflerle, transkripsiyonun başlama noktası +1 ile, intronlar ile 5' utr ve 3'utr bölgeleri küçük harfle gösterilmiştir. TATA kutusu (TAAAT) ve poli adenilasyon sinyali (AATAAA) büyük harflerle ve sarı boyanmış olarak gösterilmiştir. Stop kodonu (TAA) asterisk ile gösterilmiștir.

Medaka (O. latipes) g6pd protein sekansı ile, plati balığı (Xiphophorus maculatus), zebra baliği (Danio rerio), balon baliği (Fugu rupripes), şişen balık (Tetraodon nigoviridis) ve insan (Homo sapiens) g6pd protein sekansları kullanılarak BLOSUM62 matriks algoritmasında adı geçen organizmaların \% benzerliközdeşlik oranları hesaplanmıştır (Gromiha, 2010).

Medaka g6pd geni ile plati balığı, zebra balığ1, balon balığı, şişen balık ve insan $G 6 P D$ gen ortolojisini görmek için, protein sekansları Bioedit programı kullanılarak dizilenmiş ve benzerlik-özdeşlik oranları yüzde (\%) olarak hesaplanmıştır. Sonuçta medakanın, plati balığı ile \%91-96, zebra balığı ile \%91-95, fugu ile \%8995 ,tetraodon ile \%84-90 ve insan ile \%77-88 benzerliközdeşlik oranı gösterdiği tespit edilmiştir (Tablo 2). Ensemble genom veri tabanı kullanılarak, Medaka ( $O$. latipes) g6pd geninin 7. kromozom üzerinde, 5' bandının 19,213,373-19,223,770 bölgesinde bulunduğu tespit edilmiş ve 7. kromozom üzerindeki diğer genler ve bulundukları konum belirlenmiştir. Daha sonra bu genlerin medaka ile zebra balığı ve insanda da bulunduğu bölgeler tespit edilerek, bu bölgelere göre korunmuş gen sentezi dizayn edilmiştir (Şekil 1). 
Tablo 2. Medaka (Me) ile Plati balığı (Pb), Zebra balığı (Zb), Balon balığı (Fu), Tetraodon (Te) ve insan (In) G6PD genleri arasındaki benzerlik-özdeşlik oranları.

Table 2. Identity and similarity rate between Medaka (Me) and Platyfish (Pb), Zebrafish (Zb), Fugu (Fu), Tetraodon (Te) and Human (In) $\mathrm{g} 6 \mathrm{pd} / G 6 P D$ gene.
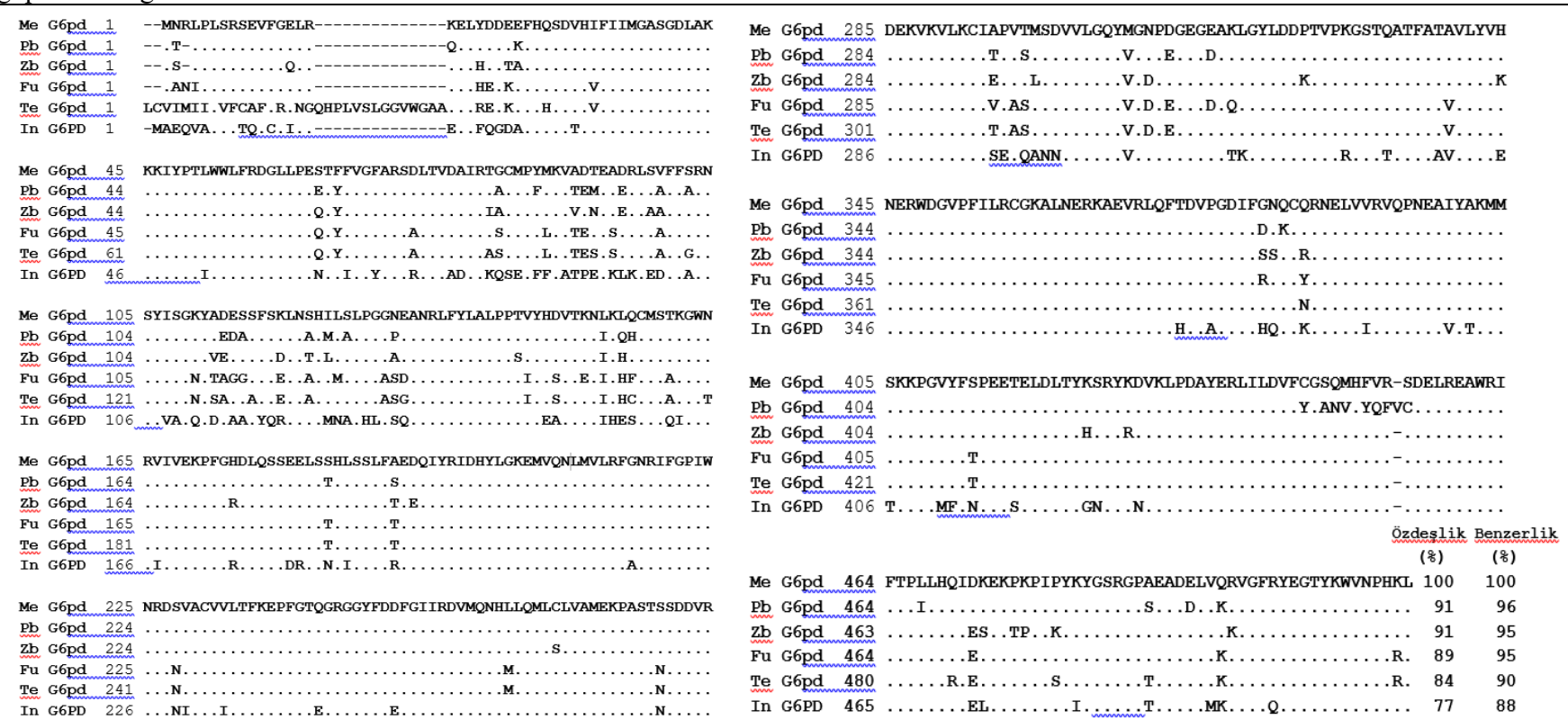

*Şekildeki noktalar benzerliği, kısa çizgiler ise belirlenemeyen aminoasitleri ifade etmektedir.

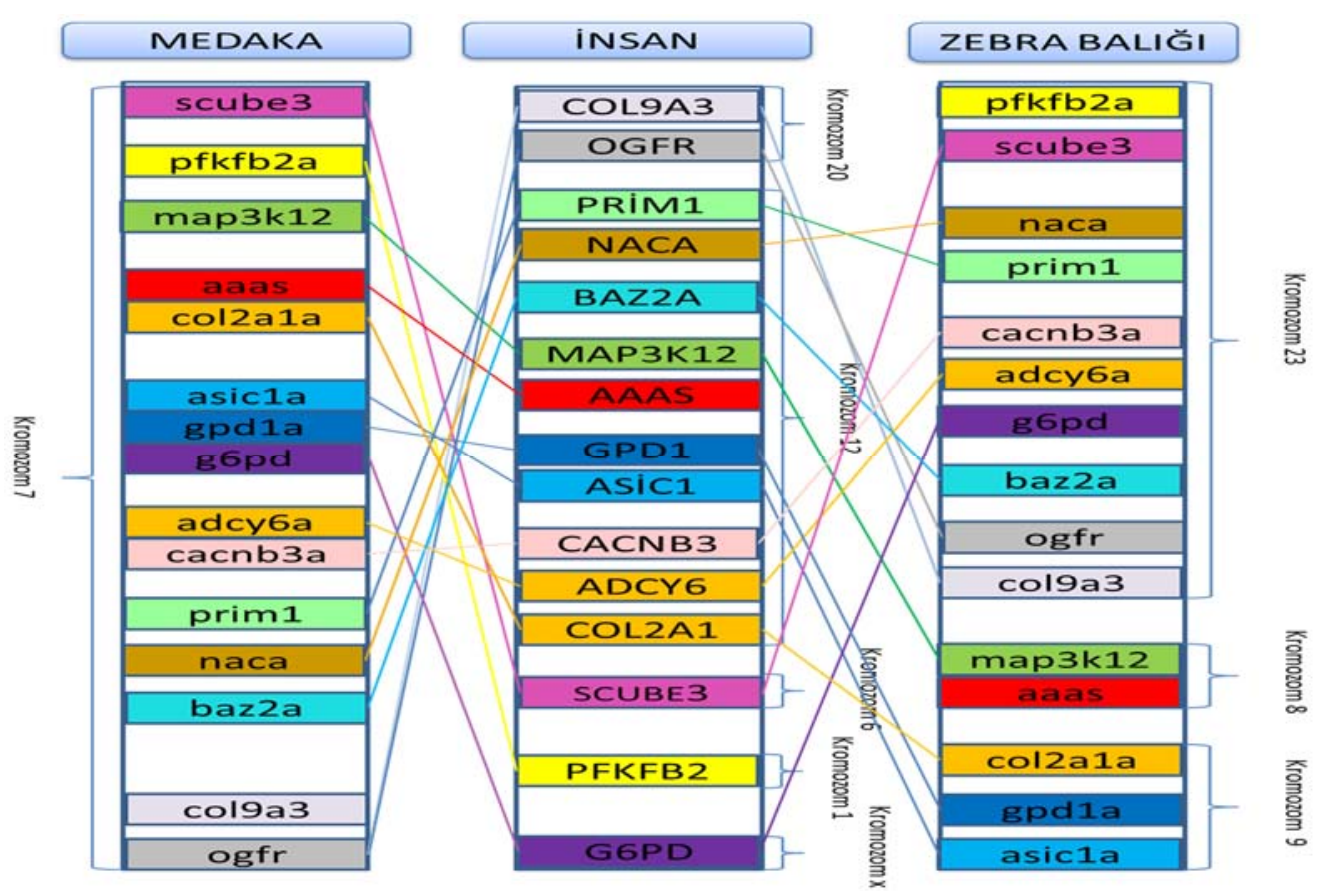

Şekil 1. Medaka g6pd geni korunmuş gen sentezi.

Figüre 1. Conserved gene synteny of Medaka $g 6 p d$ gene.

Oluşturulan korunmuş gen senzezi incelendiğinde, medaka g6pd geninin teleost tüm genom duplikasyonu sonucu meydana geldiği düşünülmektedir. Medaka $g 6 p d$ geni ile diğer teleost balıkların ve insanın g6pd/G6PD genleri arasındaki korunmuş genlerin medakada 7. kromozomda bulunan ogfr, col9a3, ncoa3, prkcbp1l, prim1, baz2a, cacnb3a, adcy6a, gpd1a, asicla, scube3, col2ala, naca, prkfb2a ve map3k12 olduğu tespit edilirken; tüm bu genlerin korunmuş olarak insanda $(1,6$, 12 ve 12 . kromozomlar üzerinde) ve zebra balığında $(8,9$ ve 23. kromozomlarda) da bulunduğu görülmüştür. Dolayısıyla medaka g6pd geninin korunmuşluk oranın 
oldukça yüksek olduğu görülmüştür (Şekil 1). Kemikli balıklarda gerçekleşen tüm genom duplikasyonu sonucunda gen kopyalarının oluştuğu bilinmekle beraber, g6pd geninin tek kopya olduğu, bu durumun ise teleost balık genlerinde görülen bir olay olan duplikasyon sonrası gen kopyalarından birinin kaybolduğu düşünülmekte ve korunmuş gen sentezide bu tezimizi desteklemektedir. Medaka (Oryzias latipes) g6pd geni (ENSORLT00000015543.2) ile omurgalı canlılar olan, zebra balığ1 (Danio rerio), (XP_021329263.1), balon balığı (Fugu rupripes) (XP_003963491.2), kirpi balı̆̆ (Tetraodon nigroviridis) (ENSTNIT00000015770.1), makobe ada çiklidi (Pundamilia nyererei) (XP_005732684.1), insan (Homo sapiens) (NP_001035810.1), adi sazan (Cyprinus carpio) (XP_018961996.1), dikenli balık (Gasterosteus aculeatus) (ENSGACT00000004022.1), fare (Mus musculus) (NP_032088.1), tavuk (Gallus gallus) (XP_024999465.1), elektrikli yılan balığı (Electrophorus electricus) (XP_026875034.1) g6pd genleri arasindaki filogenetik ilişki Mega programı ve maksimum olasılık metodu (Felsenstein, 1989) ile belirlenmiştir. Zebra balığı (Danio rerio) sod1 geni: NP_571369.1 dış grup olarak kullanılmıştır. Medakanın diğer teleost balıklar ile birlikte kümelenme gösterdiği, insan, tavuk, fare gibi medakanın ortoloğu olan canlıların ise farklı bir bölgede kümelendiği görülmüştür (Şekil 2).

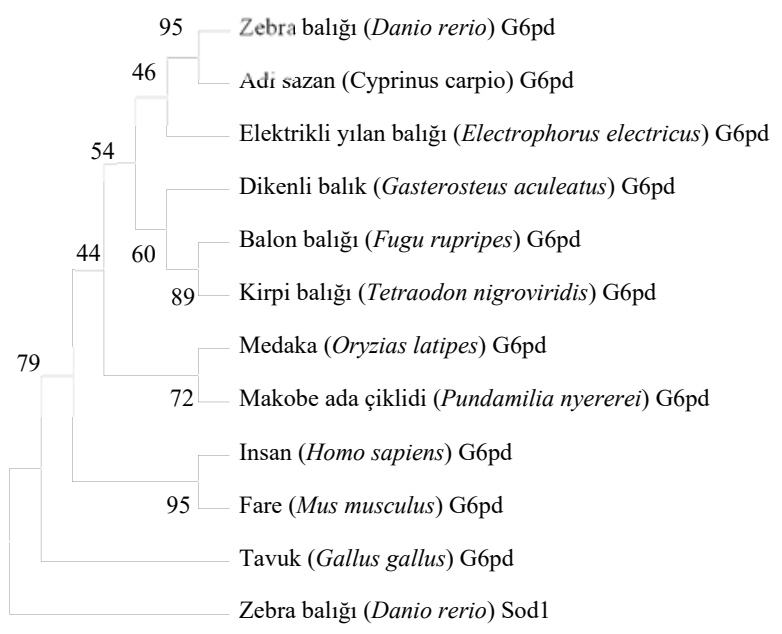

Şekil 2. Medaka $g 6 p d$ geni ile diğer teleost balıklar ve medakanın ortologları arasındaki filogenetik ilişki (maksimum olasılık metodu).

Figure 2. Phylogenetic relationship between Medaka and its orthologs $g 6 p d$ gene (Maximum likelihood method)

\section{SONUÇ}

Balıklardaki stres cevapları, farklı gen gruplarının üretmiş olduğu protein veya enzim gibi gen ifade ürünlerinin etkilerini içeren çok yönlü seviyeleri ortaya çıkarabilir. Dolayısıyla strese tepki gösteren bir model organizma ile ilgili genetik karakteristiklerin anlaşılması moleküler çalışmalar için büyük önem taşımaktadır. Balıkların stres töleransları birbirinden farklı olabildiği için, stres genlerinin ifadesi balıklar arasında farklılık göstermekte ve dolayısıyla bu genlerin karakterizasyonu ve tanımlanması, akvakültür seçim programlarında, stres toleransının geliştirilmesine yardımcı olmak için kullanılabilecek önemli veriler olarak kullanılmaktadır. Ayrıca insan başta olmak üzere pek çok omurgalı için bilimsel çalışmalarda model organizma olarak kullanılan medaka'da antioksidan enzim genlerinden biri olan g6pd'nin (Iwama et al., 1999) biyoenformatik çalışmalarının tamamlanması önemli genetik belirteçler sağlayacaktır. Bu nedenle, çalışmada biyoenformatik veri tabanları ve programlar kullanarak medaka (O. latipes)' da antioksidan enzim genlerinden olan g6pd'nin karakterizasyonu ve tanımlanması yapılmıştır.

\section{KAYNAKLAR}

Aytekin, T. \& Kargın, F. (2019). Effect of Copper on G6PD Activity in the Liver, Gill, Kidney and Muscle Tissues of Oreochromis niloticus. Anatolian Environment and Animal Sciences, 4(2), 60-63.

Bartosz, G. (2003). Generation of reactive oxygen species in biological systems. Comments on Toxicology, 9, 5-21.

Basu, S., Binder, R.J., Suto, R., Anderson, K.M. \& Srivastava, P.K. (2000). Necrotic but not apoptotic heat shock proteins, which deliver a partial maturation signal to dentritic cells and activate the NF-kB pathway. International Immunology, 12, 1539-1546.

Bayır, A. (2002). Canlı (Gammarus pulex) ve Yaş (sı̆̆ır dalăgl) Yemin Gökkuşăg (Oncorhynchus mykiss) Yavrularina Belirli Aralıklarla Verilmesinin Glukoz 6 Fosfat Dehidrogenaz ve Karbonik Anhidraz Enzim Aktiviteleri ile Büyüme, Yem Değerlendirme ve Yaşama Gücü Üzerine Etkileri. Yüksek Lisans Tezi, Atatürk Ünivesitesi Fen Bilimleri Enstitüsü, Su Ürünleri Anabilim Dalı, Erzurum. 154s.

Becker, K., Rahlfs, S., Nickel, C., \& Schirmer, R.H. (2003). Glutathione-functions and metabolism in the malarial parasite Plasmodium falciparum. Biological Chemistry, 384, 551-566.

Buechter, D.D. (1988). Free radicals and oxygen toxicity. Pharmaceutical Research, 5(5), 253-260.

Bonsignore, A., Fornaini, G., Leoncini, G., Fontani, A. \& Segni, P. (1966). Characterization of leucocyte glucose 6 phoshate dehydrogenase in Sardinian 
Mutants. Journal of Clinical Investigation, 45, 1216.

Bonsignore, A., \& De Flora, A. (1972). Regulatory properties of glocose 6-phosphate dehydrogenase. Current Topics in Developmental Biology, 6, 2162.

Filho, W.D., Torres, M.A., Marcon, J.L., Fraga, C.G. \& Boveris, A. (2000). Comparative antioxidant defences in vertebrates-emphasis on fish and mammalians. Trends in Comparative Biochemistry and Phsiology, 7, 33-45.

Gromiha, M.M. (2010). Protein sequence analysis. In: Protein Bioinformatics: From Sequence to Function. Elsevier Inc., New Delhi, India, 29-62p.

Halliwell, B. (1991). Reactive oxygen species in living system: source, biochemistry, and role in human disease. The American Journal of Medicine, 91, 14-22.

Iwama, G.K., Vijayan, M.M., Forsyth, R.B. \& Ackerman, P.A. (1999). Heat shock proteins and physiological stress in fish. American Zoology, 39, 901-909.

Kan, B., London, I.M. \& Levin, D.H. (1988). Role of reversing factor in the inhibition of protein synthesis initiation by oxidized gluthatione. Journal of Biological Chemistry, 263, 1565215656.

Kell, A.J.E., Yamins, D.L.K., Shook, E.N. \& NormanHaignere S.V . (2018). A Task-Optimized Neural Network Replicates Human Auditory Behavior, Predicts Brain Responses, and Reveals a Cortical Processing Hierarchy. Neron, 98(3), 630-644.

Lehninger, A.L., Nelson D.L. \& Cox, M.M. (2000). Principles of Biochemistry, 2nd ed., Worth Publishers Inc. New York, 558-560.

Lushchak, V.I. (2011). Environmentally induced oxidative stress in aquatic animals. Aquatic Toxicology, 101, 13-30.

Miclet, E., Stoven, V., Michels, P.A., Opperdoe, F.R. \& Lallemand J.Y. (2001). NMR spectroscopic analysis of the first two steps of the pentosephosphate pathway elucidates the role of 6phosphogluconolactonase. Journal of Biological Chemistry, 276, 34840-34846.
Naruse, K., Fukamachi, S., Mitani, H., Kondo, M., Matsuoka, T., Kondo, S., Hanamura, N., Morita, Y., Hasegawa, K., Nishigaki, R., Shimada, A., Wada, H., Kusakabe, T., Suzuki, N., Kinoshita, M., Kanamori, A., Terado, T., Kimura, H., Nonaka, M. \& Shima, A. (2000). A detailed linkage map of medaka, Oryzias latipes: comparative genomics and genome evolution. Genetics, 154, 1773-1784.

Tamura, K., Stecher, G., Peterson, D., Filipski, A. \& Kumar, S. (2013). MEGA6: Molecular Evolutionary Genetics Analysis Version 6.0. Molecular Biology and Evolution, 30(12), 27252729.

Thompson, J.D., Higgins, D.G. \& Gibson, T.J. (1994). CLUSTAL W: improving the sensitivity of progressive multiple sequence alignment through sequence weighting, positions-specific gap penalties and weight matrix choice, Nucleic Acids Research, 22, 4673-4680.

Trachootham, D., Lu, W., Ogasawara, M. A., Valle, N. R.-D. \& Huang, P. (2008). Redox regulation of cell survival. Antioxidants \& Redox Signaling, 10(8), 1343-1374.

Pilz, R.B., Willis, R.C. \& Boss, G.R. (1984). The influence of ribose-5-phosphate availability on purine synthesis of cultured human lymphoblasts and mitogen- stimulated lymphocytes. Journal of Biological Chemistry, 259, 2927-2935.

Porter, N.A., Caldwell, S.E. \& Mills, K.A. (1995). Mechanisms of free radical oxidation of unsaturated lipids. Lipids, 30, 277-290.

Yamamoto, T. (1951). Artificial sex-reversal in the genotypic males of the medaka, Oryzias latipes. The Japanese Journal of Genetics, 26, 245. 